\title{
Eel osmotic stress transcriptional factor 1 (Ostf1) is highly expressed in gill mitochondria-rich cells, where ERK phosphorylated
}

William KF Tse ${ }^{1,2^{*}}$, Sheung C Chow ${ }^{1}$ and Chris KC Wong ${ }^{1 *}$

\begin{abstract}
Background: Osmotic stress transcriptional factor 1 (Ostf1) was firstly identified in tilapia in 2005. Then numerous studies have investigated its regulation and expression profile in fish gill tissues in related to osmoregulation. Generally, hyperosmotic stress induced ostf1 mRNA expression level, however there is no report studying the cellular localization of Ostf1 expression in any osmoregulatory tissue. In this study immunohistochemical (IHC) approach was used to study the cellular localization of Ostf1 in gill cells of Japanese eels.

Findings: Ostf1 protein was found to be localized in branchial mitochondria-rich/chloride cell (MRC/CC) as revealed by Naa 5 and CFTR co-localization. The protein was detectable at day 3 after fresh water to seawater transfer and was mainly localized in MRCs. Moreover, elevated levels of extracellular signal regulated kinase (ERK) phosphorylation was observed at day 3 of the transfer and was co-localized with MRCs.

Conclusions: Our data identified Ostf1 expression in gill MRCs. The observation supports the role of Ostf1 in osmosensing and/or osmoregulation in fish gills, particularly its functional relationship with MRCs. The observation of the co-expression of pERK and Ostf1 in MRCs suggests a cross-talk mechanism between the mitogen-activated protein kinases (MAPKs) and Ostf1 in response to hyperosmotic challenge. To summarize, this report has addressed the cellular localization of Ostf1 and provides evidence to illustrate the involvement of Ostf1 and ERK on osmosensing and osmoregulatory function of gill MRCs.
\end{abstract}

Keywords: Immunohistochemical staining, Mitochondria-rich cells, Osmotic stress transcriptional factor 1

\section{Background}

Osmotic stress transcriptional factor 1 (Ostf1) was discovered through subtractive hybridization to compare the gene expression profiles between gill tissues of freshwater and seawater adapted tilapia [1]. Ostf1 is then classified as an immediate early gene in response to hyperosmotic challenge in fish [2]. Our laboratory has cloned the eel Ostf1 and conducted several in vivo and in vitro experiments to unfold the regulation of the gene expression in fish gills. We have shown that ostf1 mRNA expression levels were increased in both gill tissues and primary gill cell culture upon hyperosmotic challenge $[3,4]$. In the other study, we have also shown

\footnotetext{
* Correspondence: kftse@partners.org; ckcwong@hkbu.edu.hk

'Department of Biology, Hong Kong Baptist University, Kowloon Tong, Hong Kong

Full list of author information is available at the end of the article
}

that hyperosmotic challenge stimulated phosphorylation of extracellular signal regulated kinase (ERK) in primary eel gill cell culture [5]. The data suggest the potential importance of ERK in osmosensing and the regulation of its downstream targets. Although the importance of ERK signaling and Ostf1 expression was highlighted, currently no data on the cellular localization of Ostf1 and ERK phosphorylation in fish gills are reported.

During freshwater to seawater acclimation, the number of gill mitochondria-rich cells (MRCs) is significantly increased. The cells are believed to play an important role in hypo-osmoregulation via the expression of various ion transporters and channels to facilitate ion transport [6-8]. Using Percoll isolation and real-time RT-PCR, we reported that eel gill MRCs expressed higher level of ostf1 mRNA than the gill pavement cells [4]. On the basis of these observations, we hypothesized
C Biomed Central 
that gill MRCs utilize ERK signaling as one of the osmosensing cascade, to mediate Ostf1 and ion transporter/ channel expression. By using double immunohistochemical (IHC) staining, we identified gill MRCs and examined the spatial and temporal co-localization of Ostf1 and p-ERK at different time points after freshwater to seawater transfer. In this short report, we show the colocalization of Ostf1 and pERK in gill MRCs. The observation extends our previous published data, and also provides new data on the temporal and spatial interaction of the osmotic stress signal, pERK and Ostf1 in gill MRCs.

\section{Result and discussion}

Ostf1 expression is localized in gill MRCs in the course of freshwater to seawater transfer

To reveal the cellular localization of Ostf1 expression in fish gills, we performed IHC staining. MRCs were identified by both Na 55 and CFTR antibodies, those are the most useful tools to study MRCs in different fish species $[7,8]$. Together with the commercial available Ostf1 antibody, double staining with Naa 5 or CFTR was conducted. In tracking the pattern of Na 55 staining in the gill sections of seawater acclimating fish, the number of the positively stained cells were reduced in the secondary lamellae but was increased in the primary filament (Figure 1A-1D). This observation is consistent with our previous report, indicating that hyperosmotic challenge activated gill cell-remodeling to facilitate salt excretion process [7]. The appearance of cystic fibrosis transmembrane regulator (CFTR)-positively stained MRCs in the primary filaments at day 3 of the seawater transfer supports this claim (Figure 1E-1H). The specific staining of CFTR was observed to be localized at the apical pits of gill MRCs. In the IHC staining, Ostf1 protein was detectable at day 3 of the seawater transfer and its expression was found to be localized in MRCs. The co-localizations of the Na 5 /CFTR and Ostf1 proteins in MRCs were shown (Figure 1C-1D, 1G-1H). Furthermore our data showed that Ostf1 protein was detectable in the cytoplasm of MRCs (Figure 1E-1H), except the apical region of the cells (Figure 1M). It is not surprised that the Ostf1 staining observed in most cytoplasm of MRCs, as other ion transporters such as sodium bicarbonate co-transporter and aquaporin 3 had been reported to have similar staining pattern. It is probably due to the extensive internal membrane folding of MRCs $[7,8]$.

\section{Induction of ERK phosphorylation in gill MRCs after freshwater to seawater transfer}

Hyperosmotic stress triggers phosphorylation of different mitogen-activated protein kinases (MAPKs) $[9,10]$. In vitro studies of eel primary gill cell culture have shown that hypertonic challenge activated ERK phosphorylation within 2 minutes and returned back to the basal level in 30 minutes [5]. Using IHC staining in the in vivo whole animal experiment, the present study reported the cellular localization of phosphorylated ERK in gill tissues at day 3 after freshwater to seawater transfer (Figure 1I-1L). The onset and the duration of MAPK activation might be difference between the in vitro and in vivo studies. It can be explained by the differences in the experimental settings, in the methods of preparation and detection as well as in the time-window of cellular signal activation. In general, the experimental setting of in vitro primary gill cell culture provides a direct exposure of the monolayer cells to osmotic challenges, leading to a fast cellular response to the stimulation. On the contrary, in the whole animal in vivo studies, although gill tissue is also in direct contact with the external environment, the tissues were mostly protected by mucous secretion to minimize the magnitude of osmotic shock. In addition, the existence of other compensatory mechanisms in fish for anisosmotic adaptation might result in a lesser osmotic impact and so a relatively slower response from the gill cells. Moreover, the use of different tissue preparation and protein detection methods would lead to different extents of protein preservation and sensitivity of the detection. There shall be a great difference when comparing the data of IHC and Western blotting [7,8]. Furthermore, the detection of early ERK activation in primary gill cell culture does not mean inconsistence to the appearance of phosphorylated ERK in gill MRCs at day 3 of the seawater transfer. This can be explained by the biphasic response of ERK signaling, orchestrating diverse stimuli from osmotic challenge and gill remodeling processes. With the benefit of hindsight, the activation of ERK-signaling during gill remodeling highlights the importance of this signaling pathway in osmosensing and osmoregulatory function of the cells. It is particularly true that numerous reports have shown the importance of MAPK pathways in the regulation of various ion channels/transporters, including aquaporin, Cftr, sodiumhydrogen exchanger, and $\mathrm{Na}^{+} / \mathrm{K}^{+}$-ATPase [11-14]. It is noteworthy that not all MRCs showed elevated phosphorylated ERK at day 3 of the seawater transfer (Figure $1 \mathrm{~K})$. However, all MRCs were p-ERK positive at day 7 of the transfer (Figure 1L-1N). Nevertheless, the co-localization of Ostf1 and pERK in MRCs that we reported in this study, suggests the co-operative function of Ostf1 and pERK in MRCs to facilitate functional transformation to stimulate different ion channels and transporters for long-term adaptation.

\section{Materials and methods}

Animals

Japanese eels weighing 500-600 g were bought from the local fish market (Lok Fu, Hong Kong) and kept in two 


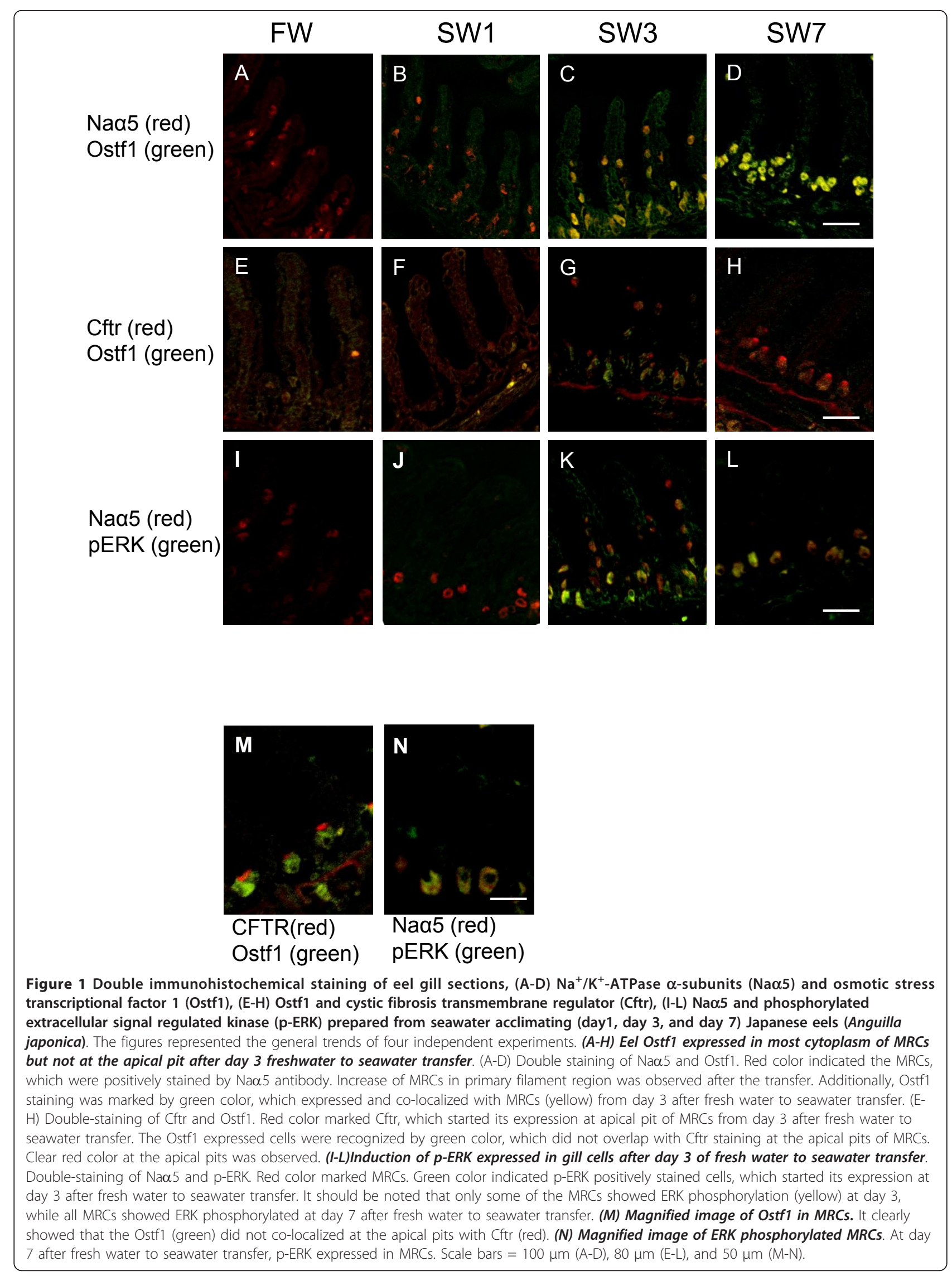


$40 \mathrm{~L}$ fiberglass tanks supplied with charcoal-filtered aerated fresh water at $18-20^{\circ} \mathrm{C}$ under a $12 \mathrm{~h}$ light: $12 \mathrm{~h}$ dark photoperiod for at least 3 weeks. Ten liters of the water were changed every 3 days. Some fish $(\mathrm{n}=12)$ were then transferred directly to freshwater tank (as the transfer control) and seawater tanks. Both freshwater and seawater transferred fish were sampled at designated time points (days 1, 3, and 7). Three fish were samples at each time point from the freshwater and the seawater tanks. The experiment was then repeated independently for 4 times. The fish were euthanized with $0.1 \%$ MS222 in a plastic container and the gills were perfused with buffered saline $(130 \mathrm{mM} \mathrm{NaCl}, 2.5 \mathrm{mM}$ $\mathrm{KCl}, 5 \mathrm{mM}$ NaHCO3, $2.5 \mathrm{mM}$ glucose, $2 \mathrm{mM}$ EDTA, and $10 \mathrm{mM}$ Hepes, pH 7.7) to remove blood cells. Gill arches were excised and washed. One of the gill arches (first left gill arch) was fixed for IHC staining. All experimental procedures on the fish were approved by Hong Kong Baptist University, Hong Kong Special Administrative Region.

\section{Immunohistochemical (IHC) staining}

A paraformaldehyde-fixed wax section of the gill tissue (6 $\mu \mathrm{m}$ thickness) was de-waxed, rehydrated in graded ethanol, and rinsed in phosphate-buffered saline (PBS). The staining procedure involved pretreatment of the tissue section with $10 \%$ normal goat serum in PBS to reduce nonspecific binding, followed by an hour incubation at room temperature with antiserum (i.e. mouse anti- $\mathrm{Na}^{+} / \mathrm{K}^{+}$-ATPase $\alpha$-subunits (Na $\alpha$ ) (1:100, Hybridoma Bank), rabbit anti-pERK (1:100, Cell Signaling), and rabbit anti-GilZ/TilZ (1:100, Abcam). The section was rinsed in PBS, incubated with Alexa Fluor 488 or 568 goat anti-mouse/anti-rabbit IgG (1:200, Molecular Probes), and examined by a laser confocal microscope (Fluoview, Olympics). The slides were washed 3 times for 15 minutes each in PBS after each antiserum application. The control procedure included the application of non-immune mouse or rabbit serum (Sigma) (Additional file 1: Figure S1). Eel Ostf1 encodes TSC22 (GilZ/ TilZ) domain, which was recognized by the anti-GilZ/ TilZ antibody. The antibody recognizes the carboxyl terminus of mouse GilZ/TilZ that shares high amino acid sequences homology in eel GIlZ/TilZ domain. The specificity of the antibody was confirmed by Western blotting. Specific band at $30 \mathrm{kDa}$ was marked (Additional file 1: Figure S2).

\section{Additional material}

\section{Additional file 1: Figure S1 Negative control of} immunohistochemical staining experiments using the non-immune mouse or rabbit serum. No positive signals of Ostf1, pERK, and Cftr were found in the gill epithelia prepared from Japanese eels (Anguilla japonica) acclimated in seawater (day 7). Scale bar $=80 \mu \mathrm{m}$. Figure S2: The specificity of the Ostf1 antibody was confirmed by Western blotting. A band at $30 \mathrm{kDa}$ was identified in the gill sample. Actin was used as the loading control.

\section{Abbreviations}

CC: Chloride cell; ERK: Extracellular signal regulated kinase; IHC: Immunohistochemical; MAPK: Mitogen-activated protein kinase; MRC: Mitochondria-rich cell; Ostf1: Osmotic stress transcriptional factor 1.

\section{Acknowledgements}

This work was supported by General Research Fund (HKBU 261610), University Grants Committee to CKCW.

\section{Author details}

'Department of Biology, Hong Kong Baptist University, Kowloon Tong, Hong Kong. ${ }^{2}$ Center for Regenerative Medicine, Massachusetts General Hospital, Harvard Medical School, Boston, Massachusetts, USA.

\section{Authors' contributions}

CKCW and WKFT designed the experiment and wrote the manuscript. WKFT carried out the IHC experiments. SCC preformed the Western blotting. All authors read and approved the final manuscript.

\section{Competing interests}

The authors declare that they have no competing interests.

Received: 9 November 2011 Accepted: 10 March 2012

Published: 10 March 2012

\section{References}

1. Fiol DF, Kultz D: Rapid hyperosmotic coinduction of two tilapia (Oreochromis mossambicu) transcription factors in gill cells. Proc Natl Acad Sci USA 2005, 102:927-932.

2. Fiol DF, Chan SY, Kultz D: Regulation of osmotic stress transcription factor 1 (Ostf1) in tilapia (Oreochromis mossambicu) gill epithelium during salinity stress. J Exp Biol 2006, 209:3257-3265.

3. Tse WKF, Au DW, Wong CK: Effect of osmotic shrinkage and hormones on the expression of $\mathrm{Na}^{+} / \mathrm{H}^{+}$exchanger-1, $\mathrm{Na}^{+} / \mathrm{K}^{+} / 2 \mathrm{Cl}^{-}$cotransporter and $\mathrm{Na}^{+} / \mathrm{K}^{+}$-ATPase in gill pavement cells of freshwater adapted Japanese eel, Anguilla japonic. J Exp Biol 2007, 210:2113-2120.

4. Tse WKF, Chow SC, Wong CKC: The cloning of eel osmotic stress transcription factor and the regulation of its expression in primary gill cell culture. J Exp Bio/ 2008, 211:1964-1968.

5. Chow SC, Wong CKC: The regulatory functions of hypertonic stressinduced signaling cascades to the expressions of osmotic stress transcriptional factors and osmolytes transporters in primary gill cell culture of freshwater japanese eels. J Exp Biol 2011, 214:1264-1270.

6. Evans DH, Piermarini PM, Choe KP: The multifunctional fish gill: dominant site of gas exchange, osmoregulation, acid-base regulation, and excretion of nitrogenous waste. Physiol Rev 2005, 85:97-177.

7. Tse WKF, Au DWT, Wong CKC: Characterization of ion channel and transporter mRNA expressions in isolated gill chloride and pavement cells of seawater acclimating eels. Biochem Biophys Res Commun 2006, 346:1181-1190.

8. Tse WKF, Wong CKC: nbce and -atpas mRNA expression are stimulated in the mitochondria-rich cells of freshwater acclimating Japanese eels (Anguilla japonic). Can J Zool 2011, 89:348-355.

9. de Nadal E, Alepuz PM, Posas F: Dealing with osmostress through MAP kinase activation. EMBO Rep 2002, 3:735-740.

10. Burg MB, Ferraris JD, Dmitrieva NI: Cellular response to hyperosmotic stresses. Physiol Rev 2007, 87:1441-1474.

11. Pesce L, Guerrero C, Comellas A, Ridge KM, Sznajder Jl: $\beta$-Agonists regulate $\mathrm{Na}$, K-ATPase via novel MAPK/ERK and rapamycin-sensitive pathways. FEBS L 2000, 486:310-314.

12. Goss GG, Jiang L, Vandorpe DH, Kieller D, Chernova MN, Robertson M, Alper SL: Role of JNK in hypertonic activation of $\mathrm{Cl}$-dependent $\mathrm{Na}+/ \mathrm{H}+$ 
exchange in Xenopus oocytes. Am J Physiol Cell Physiol 2001, 281: C1978-C1990.

13. Umenishi F, Schrier RW: Hypertonicity-induced Aquaporin-1 (AQP1) expression is mediated by the activation of MAPK pathways and hypertonicity-responsive element in the AQP1 gene. J Biol Chem 2003, 278:15765-15770.

14. Maruyama T, Kadowaki H, Okamoto N, Nagai A, Naguro I, Matsuzawa A, Shibuya H, Tanaka K, Murata S, Takeda K, Nishitoh H, Ichijo H: CHIPdependent termination of MEKK2 regulates temporal ERK activation required for proper hyperosmotic response. EMBO J 2010, 29:2501-2514.

doi:10.1186/1742-9994-9-3

Cite this article as: Tse et al.: Eel osmotic stress transcriptional factor 1 (Ostf1) is highly expressed in gill mitochondria-rich cells, where ERK phosphorylated. Frontiers in Zoology 2012 9:3.

Submit your next manuscript to BioMed Central and take full advantage of:

- Convenient online submission

- Thorough peer review

- No space constraints or color figure charges

- Immediate publication on acceptance

- Inclusion in PubMed, CAS, Scopus and Google Scholar

- Research which is freely available for redistribution

Submit your manuscript at www.biomedcentral.com/submit
() Biomed Central 